\section{O ESPORTE COMO UM DIREITO: TRAÇOS E TRAMAS DA CONSTITUIÇÃO DE UMA VERDADE}

SPORT AS A RIGHT: TRAITS AND PLOTS OF FORMATION OF TRUTH

DEPORTE COMO UN DERECHO: RASGOS Y GRÁFICOS DE FORMACIÓN DE $\angle A$ VERDAD

Rose Meri Silva*, Méri Rosane Silva**
Palavras-chave

Esportes.

Constituição

e estatutos.

Filosofia

Resumo: Este artigo tem como objetivo problematizar o estatuto de verdade assumido pelo esporte no Brasil, que o produz como um direito, garantido pelo Estado a todo e qualquer cidadão. Em termos de investimento metodológico, foram acionadas algumas ferramentas da genealogia foucaultiana, absolutamente imbricada com a arqueologia, adotando-se, como corpus de análise, as leis e decretos que foram implementados a partir da Constituição de 1988. Ao finalizar este trabalho, evidenciaram-se enunciados diversos, compondo, assim, um regime de verdade que busca produzir o esporte enquanto um direito naturalmente aceito e sempre presente na vida de todo e qualquer brasileiro.

Abstract: This article aims at debating the status of truth taken on by sport in Brazil, which produces it as a right that is guaranteed by the State to every citizen. Methodology included some tools of Foucaltian genealogy, which is absolutely imbricated with archeology. Laws and decrees implemented since the 1988 Constitution were adopted as a corpus of analysis. The work found many statements that make up a truth regime that seeks to produce sport as a naturally accepted right that is always present in the lives of all Brazilians.

Palabras clave

Deportes. Constitución y estatutos.

Filosofía.
Resumen: Este artículo tiene como objetivo problematizar el estatuto de verdad asumido por el deporte en Brasil, que lo produce como un derecho, garantizado por el Estado a todo y cualquier ciudadano. En términos de inversión metodológica, fueron accionadas algunas herramientas de la genealogía foucaultiana, absolutamente imbricada con la arqueología, adoptando, como corpus de análisis, las leyes y decretos que fueron implementados a partir de la Constitución de 1988. Al finalizar este trabajo, se evidenciaron enunciados diversos, componiendo, así, un régimen de verdad que busca producir el deporte como un derecho naturalmente aceptado y siempre presente en la vida de todo y cualquier brasileño.
*Universidade Federal de Pelotas. Pelotas, RS, Brasil.

E-mail: roseufpel@yahoo.com.br

** Universidade Federal de Pelotas. Pelotas, RS, Brasil.

E-mail: meri.rosane@ hotmail.com

Recebido em: 26-03-2014 Aprovado em: 23-09-2014 (c) (1) (8) Licence 


\section{CONSIDERAÇÕES INICIAIS}

Evoco as palavras proferidas por Nietzsche para adentrar no emaranhado constitutivo do presente texto, que foi elaborado com o objetivo de problematizar o estatuto de verdade assumido pelo esporte no Brasil como um direito garantido pelo Estado a todo e qualquer cidadão.

Dito isso, abre-se um relicário de onde emergem algumas noções relevantes, e que precisam ser enfatizadas para a realização deste trabalho, que se movem impulsionadas pela curiosidade de pensar nossas ações cotidianas. Destaco, inicialmente, que faço alusão à noção de problematizar não no sentido de desconstruir algo ou mesmo de questionar se uma instância é verdadeira ou falsa, certa ou errada, válida ou inválida. Reporto-me, isso sim, a diagnosticar' "o conjunto das práticas discursivas ou não discursivas que faz alguma coisa entrar no jogo do verdadeiro e do falso e o constitui como objeto para o pensamento" (FOUCAULT, 1984, p. 242).

Ressalto, ainda, que não me dedico a abordar uma analítica da verdade, percebida como um dado naturalmente concebido ou como "o conjunto das coisas verdadeiras a descobrir ou a fazer aceitar", mas, isso sim, como o "[...] conjunto das regras segundo as quais se distingue 0 verdadeiro do falso e se atribui ao verdadeiro efeitos específicos de poder" (FOUCAULT, 1979, p. 11). Refiro-me a algo que se poderia chamar de uma análise histórica do presente, ou seja, "[...] o infindável questionamento sobre o que nos tornamos historicamente, as 'verdades' a que nos submetemos e que incorporamos, e que fizeram de nós aquilo que hoje somos" (ASSMANN, 2007, p. 3).

Especificamente, neste trabalho, dedico-me a problematizar como foi se produzindo, na esfera da história da sociedade brasileira, essa verdade que coloca o esporte em uma ordem discursiva que o considera como um direito. Quais os regimes de verdade que o sustentam e 0 produzem nessa condição de um direito? Quais as condições e possibilidades que passaram a vigorar e a se entrecruzar produzindo um campo de existência do esporte como um direito de cada cidadão brasileiro? Essas são algumas das indagações e anseios que o presente texto se propõe a tratar, buscando assim "[...] reencontrar as conexões, os encontros, os apoios, os bloqueios, os jogos de força, as estratégias etc., que, em um dado momento, formaram o que, em seguida, funcionará como evidência, universalidade, necessidade" (FOUCAULT, 1980c, p. 339).

Entretanto, não faço alusão a uma noção determinada de esporte, nem me atenho a saber o que ele é mesmo, assim como não é de meu interesse determinar qual concepção esteja sendo utilizada: de rendimento, de participação ou qualquer que seja sua forma de nomeação e delineamento. Não me movo pela busca de uma conceituação correta, nem por uma defesa de determinada compreensão de esporte em detrimento de outras, o que me impulsiona é compreender o cotidiano, a realidade como ela se apresenta, como se constitui no momento presente. Sendo assim, o que se torna produtivo, para essa investigação, é problematizar a condição que o esporte assumiu no Brasil, sendo considerado um direito, garantido pelo Estado, a todo e qualquer cidadão.

1 Diagnosticar refere-se a "estabelecer o que constitui nosso presente, os acontecimentos que repetimos [...]. Não se trata de compreender 0 presente a partir do passado (como uma época do mundo) nem do futuro (como anúncio ou promessa), mas em sua diferença, a partir de si mesmo" (CASTRO, 2009, p. 107). 
Para tornar viável tal empreendimento, lanço como proposta realizar uma análise absolutamente imbricada e movida pelo legado deixado por Michel Foucault, pois, como nos aponta Vilela (2006, p. 114), o "[...] pensamento de Michel Foucault ajuda-nos a pensar a arquitetura e o guião desse teatro onde a cortina nunca cai; ele permite-nos perspectivar o modo como as relações entre o poder e a vida se jogam no palco da história".

Também é na trajetória dos estudos desenvolvidos por Foucault que encontro pistas, ou mesmo algumas ferramentas produtivas, em termos de investimento metodológico, para serem acionadas neste texto, mas sempre atenta às palavras de Artierès (2006, p. 22), ao mencionar que o interesse de Michel Foucault "[...] não eram as marcas que mostravam o como ele tinha escrito seus livros e sim, como os usuários de seus livros tinham deles se apropriado, como eles tinham trabalhado com eles".

É dentro desse panorama que uma atitude genealógica², absolutamente imbricada com a arqueologia ${ }^{3}$, se efetiva como uma inspiração metodológica nesta produção textual, que se faz impulsionada pela curiosidade de pensar como o esporte, enquanto um direito de todo 0 cidadão, entrou em cena na história da sociedade brasileira. Refiro-me a ativar algumas ferramentas, dessa postura de fazer pesquisa operada por Foucault, para compreender quais as séries de condições, as estratégias, os saberes e os poderes que se entrelaçam e passam a atuar na história do Brasil, colocando o esporte em uma ordem discursiva que o considera um direito de todo cidadão.

\section{ADENTRANDO NA MASSA DOCUMENTAL}

Para tornar possível tal empreendimento analítico, faz-se necessário definir sobre qual material lançar meu olhar? Quais delineamentos podem ser ativados para compor os documentos a serem trabalhados enquanto um corpus de análise ${ }^{4}$ ? Que fragmentos recolher para fazer funcionar a presente investigação?

É novamente no legado foucaultiano que vou encontrar algumas pistas com potencial para serem utilizadas, pois é na Arqueologia do Saber que ele nos aponta que o "documento não é o feliz instrumento de uma história que seria em si mesma, e de pleno direito, memória" (FOUCAULT, 2002, p. 8), nem mesmo ele deve ser escolhido para reconstituir o que queriam dizer, se diziam a verdade, ou mesmo, para "memorizar' os monumentos ${ }^{5}$ do passado" (FOUCAULT, 2002, p. 8). Sua ação deve se dar no sentido de demarcar o acontecimento de determinadas práticas, inscritas no tempo da história, em um movimento que permita ir dos documentos aos monumentos (FOUCAULT, 2002, p. 8).

Especificamente neste trabalho refiro-me a utilizar, como corpus de análise, as leis e decretos que foram implementados a partir da Constituição de 1988, compondo assim enunciados de um discurso legislativo que busca produzir, enquanto verdade, o esporte como um direito de cada brasileiro a ser garantido pelo Estado.

\footnotetext{
2 A genealogia utilizada por Foucault pode ser considerada como "o acoplamento dos conhecimentos eruditos e das memórias locais, acoplamento que permite a constituição de um saber histórico das lutas e a utilização desse saber nas táticas atuais. [...] Trata-se da insurreição dos saberes. Não tanto contra os conteúdos, os métodos ou os conceitos de uma ciência, mas de uma insurreição, sobretudo e acima de tudo, dos efeitos centralizadores de poder que são vinculados à instituição e ao funcionamento de um discurso científico" (FOUCAULT, 2008a, p. 13-14).

3 Williams (2013, p. 163) coloca que "a arqueologia desenterra e cria o material que nos permite traçar genealogias".

4 Utilizo-me da noção de Rosa Fischer (2007, p. 43) que concebe corpus de análise como "um conjunto de textos associados a inúmeras práticas sociais".

5 Monumentos é a reunião de muitas tensões diferentes em algo que sempre requer uma interpretação adicional (WILLIAMS, 2013, p. 162).
} 
Mas por que esses documentos e não outros? O que me leva a utilizá-los como pontos de ancoragem para desenvolver minha pesquisa? O que justifica elencar esses documentos, dentre tantos outros, que operam na produção de verdade que considera o esporte no Brasil como um direito de todos e um dever do Estado?

É na ânsia de buscar, se não as respostas, alguns subsídios que auxiliem meu caminho que evoco aqui alguns princípios indicados por Foucault, em uma palestra realizada em dezembro de 1970, como necessários para empreender uma análise a partir de uma perspectiva genealógica, como aquela que nos remete à formação efetiva do discurso ${ }^{6}$ (FOUCAULT, 1996, p. 70).

Inicialmente, ele aponta o princípio da inversão, em que indica que lá onde a tradição via a fonte, a origem de um discurso, sua genealogia passa a reconhecê-lo como um recorte, uma ruptura, ou mesmo um acontecimento. A seguir, Foucault aponta o princípio da descontinuidade, em que os discursos devem ser tratados como práticas descontínuas, que se cruzam e/ou se ignoram, constituindo uma série. Posteriormente tem-se o princípio da especificidade, indicando que os discursos não devem ser tratados com significações prévias, mas como algo que impomos em todo o caso, isto é, como uma regularidade. Por último, o referido autor destaca o princípio da exterioridade, que expressa que os discursos devem ser considerados em sua aparição e regularidade, ou mesmo em suas condições de possibilidade.

É movida por esses princípios reguladores de suas pesquisas genealógicas que assumo a Constituição de 1988 enquanto um demarcador a partir do qual minhas análises serão acionadas, visto que ela foi a primeira legislação oficial do Brasil que institucionalizou o Esporte como um direito, tendo na figura do Estado o responsável por provê-lo, como podemos verificar no Título VIII - da Ordem social, no Capítulo III - Da Educação, da Cultura e do Desporto o art. 217, conforme excerto abaixo ${ }^{7}$ :

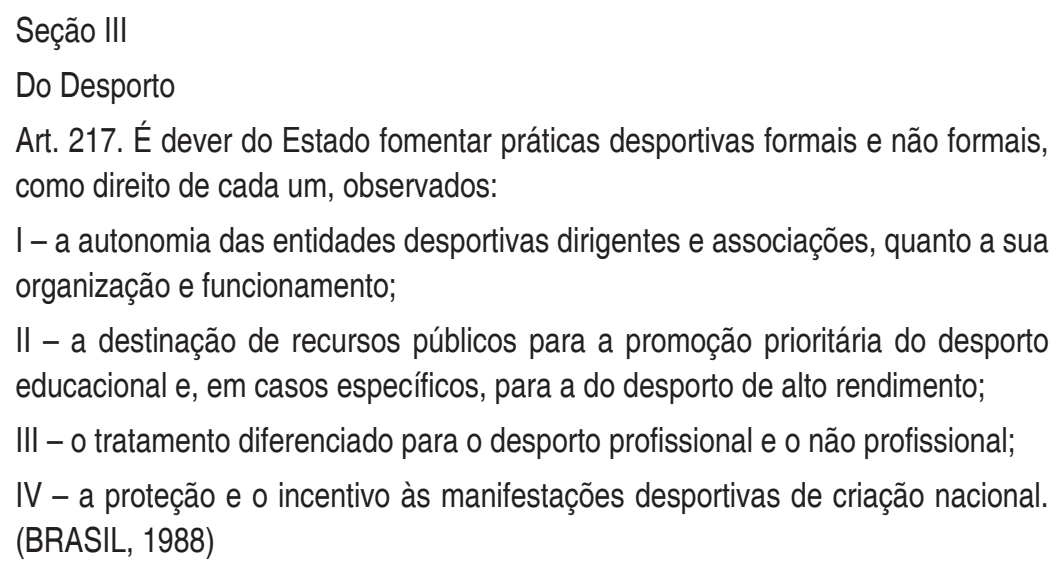

É importante destacar que não estou tomando tal legislação como um indicador de verdade, nem mesmo como sua origem, mas sua relevância está na função exercida no contexto histórico em que passa a acontecer, onde ela marca uma descontinuidade na composição de um campo discursivo. Refiro-me ao fato de que no Brasil o esporte já ocorria de diferentes modos e manifestações, compondo cenários e sendo produzido por discursos diversos, tais como o científico, o midiático ou mesmo o próprio discurso legislativo, constituído por enunciados que operavam legitimando juridicamente determinadas verdades e que aqui pode ser observado

6 Discurso é tomado aqui como o conjunto de enunciados na medida em que se apoiem em uma mesma formação discursiva. (FOUCAULT, 2002, p. 135)

7 Todos os excertos evidenciados do corpus de análise serão destacados em uma caixa de texto, conforme apresentado a seguir. 
já desde o ano de 1938, com o Decreto-Lei n 526, considerado a normatização referente ao esporte no Brasil.

Institui o Conselho Nacional de Cultura.

O Presidente da República, usando das atribuições que Ihe confere 0 art. 180 da Constituição,

DECRETA:

Art. 1ำ Fica instituído, no Ministério da Educação e Saúde, como um de seus órgãos de cooperação, o Conselho Nacional de cultura [sic].

Art. 2ㅇ 0 Conselho Nacional de Cultura será o órgão de coordenação de todas as atividades concernentes ao desenvolvimento cultural, realizadas pelo Ministério da Educação e Saúde ou sob o seu controle ou influência.

Parágrafo único. 0 desenvolvimento cultural abrange as seguintes atividades:

a) a produção filosófica, científica e literária;

b) 0 cultivo das artes;

c) a conservação do patrimônio cultural (patrimônio histórico, artístico, documentário, bibliográfico, etc.);

d) 0 intercâmbio intelectual;

e) a difusão cultural entre as massas através dos diferentes processos de penetração espiritual (o livro, o rádio, o teatro, o cinema, etc.);

f) a propaganda e a campanha em favor das causas patrióticas ou humanitárias;

g) a educação cívica através de toda sorte de demonstrações coletivas;

h) a educação física (ginástica e esportes); (BRASIL, 1938, grifo nosso)

A seguir, entra em vigor uma legislação implementada com a incumbência de realizar um primeiro estudo da situação vivida pelo esporte nacional e apresentar o plano geral de sua regulamentação (LYRA FILHO, 1952, p. 119). Refiro-me ao Decreto-Lei ํㅜ 1.056, de 19 de janeiro de 1939, conforme abaixo destacado.

Institui a Comissão Nacional de Desportos.

O PRESIDENTE DA REPÚBLICA, usando da atribuição que lhe confere 0 art. 180 da Constituição,

DECRETA:

Art. 1 Fica instituída uma comissão, denominada Comissão Nacional de Desportos que será constituída de cinco membros, designados pelo Presidente da República, dentre pessoas entendidas em matéria de Desportos ou a estes consagradas.

Art. 2 Compete à Comissão de que trata o artigo anterior realizar minucioso estudo do problema dos desportos no país, e apresentar ao Governo Federal, no prazo de sessenta dias, o plano geral de sua regulamentação.

Art. 3 Esta lei entrará em vigor na data de sua publicação, ficando revogadas as disposições em contrário.

Rio de Janeiro, 19 de janeiro de 1939, $118^{\circ}$ da Independência e 51ํㅡ da República. GETÚLIO VARGAS. (BRASIL, 1939)

Posteriormente, foi criado o Decreto-Lei no 3.199, publicado no Diário Oficial de 14/04/1941, conforme abaixo:

Estabelece as bases de organização dos desportos em todo o país

O Presidente da República, usando da atribuição que Ihe confere 0 art. 180 da Constituição, 
DECRETA:

CAPÍTULO I

DO CONSELHO NACIONAL DE DESPORTOS E DOS CONSELHOS REGIONAIS DE DESPORTOS

Art. 1ํ Fica instituído, no Ministério da Educação e Saúde, o Conselho Nacional de Desportos, destinado a orientar, fiscalizar e incentivar a prática, dos desportos em todo o país.

Art. $2^{\circ}$ O Conselho Nacional de Desportos compor-se-á de cinco membros, a serem nomeados pelo Presidente da República, dentre pessoas de elevada expressão cívi$\mathrm{ca}$, e que representem, em seus vários aspectos, o movimento desportivo nacional.

Parágrafo único. A nomeação, de que trata este artigo, será feita por um ano, não sendo vedada a recondução.

Art. $3^{\circ}$ Compete precipuamente ao Conselho Nacional de Desportos:

a) estudar e promover medidas que tenham por objetivo assegurar uma conveniente e constante disciplina à organização e à administração das associações e demais entidades desportivas do país, bem como tornar os desportos, cada vez mais, um eficiente processo de educação física e espiritual da juventude e uma alta expressão da cultura e da energia nacionais;

b) incentivar, por todos os meios, o desenvolvimento do amadorismo, como prática de desportos educativa por excelência, e ao mesmo tempo exercer rigorosa vigilância sobre o profissionalismo, com o objetivo de mantê-lo dentro de princípios de estrita moralidade;

c) decidir quanto à participação de delegações dos desportos nacionais em jogos internacionais, ouvidas as competentes entidades de alta direção, e bem assim fiscalizar a constituição das mesmas;

d) estudar a situação das entidades desportivas existentes no país para o fim de opinar quanto às subvenções que Ihes devam ser concedidas pelo Governo Federal, e ainda fiscalizar a aplicação dessas subvenções. (BRASIL, 1941)

Destaco também o Art. 1ำ (BRASIL, 1941), acima mencionado, que expressa a responsabilidade do Ministério da Educação e Saúde, na figura do Conselho Nacional de Desporto, por orientar, fiscalizar e incentivar a prática dos desportos em todo o país. Tubino (2002, p. 26) ressalta que a partir dessa legislação o Estado, mais especificamente o governo do Estado Novo, saiu da posição de reflexão para assumir uma atitude de ação em relação à regulamentação e à normatização do esporte nacional.

Percebe-se, assim, já desde a década de 1930, a implementação de toda uma gama de leis e decretos compondo enunciados de um discurso legislativo, que operava na produção e no funcionamento do esporte enquanto uma prática do cotidiano e, mais ainda, absolutamente atrelada ao contexto vivido, do mesmo modo como a definição do Estado como responsável por promover tais atividades. Para Soares (2011, p. 4), "[...] a década de 1930 apresentava-se fortemente marcada por um incentivo às práticas corporais, por políticas de Estado que estimulam e incrementam uma cultura do corpo, do vigor físico, de aparências atléticas".

Neste período, a Europa via expandir-se, em termos de organização política, experiências marcadamente autoritárias, nacionalistas, estatizantes e corporativistas, com Hitler no poder da Alemanha, Mussolini na Itália e Salazar em Portugal (PANDOLFI, 1999, p. 10). Já, no Brasil, vivia-se em um período histórico caracterizado como o Estado Novo (1937-1945), regime autoritário implantado com o golpe realizado por Getúlio Vargas, em novembro de 1937, que culminou com uma série de movimentos e de disputas vividos desde a Revolução de 1930, quando, através da luta armada, o referido governante já havia assumido a presidência da república. 
O país, até então basicamente agrário e exportador, deparou-se com mudanças significativas em seu modo de vida, pois foi se transformando numa nação urbana e industrial. Vargas buscava fortalecer um sentimento de identidade nacional e, assim, enfrentava-se uma onda de um nacionalismo bastante forte. $O$ Estado investiu na cultura e na educação, tendo como preocupação a construção de uma nova ideia de nacionalidade (PANDOLFI, 1999, p. 10). As manifestações culturais e as práticas esportivas, direcionadas à população em geral, foram densamente incentivadas, construindo-se áreas de lazer para as atividades esportivas e também estimulando-se as manifestações teatrais e cinematográficas.

A ocupação do tempo livre das pessoas vai sendo paulatinamente assumida pelo Estado, que tem seu papel bastante potencializado (BUENO, 2008, p. 97), evidenciando um deslocamento em seu modo de operar, ou seja, é uma forma de atuação governamental pautada em realizações que visavam atingir um maior número de pessoas, compreendidas como um corpo múltiplo, como um grande corpo vivo, ou mesmo como parte de uma população ${ }^{8}$.

Nessa forma de ação estatal não havia a necessidade de uma série dispendiosa de intervenções individuais, mas sim daquelas tomadas considerando os indivíduos como parte de um grupo com características específicas, uma massa populacional, que precisa ser conhecida, administrada, gerenciada e tratada a partir de suas necessidades comuns (FOUCAULT, 2006, p. 294).

Compõem-se, assim, todo um panorama em que o Estado assume um papel determinante na potencialização da vida dos indivíduos e das populações e, especificamente, em relação à existência do esporte, ele toma a incumbência de supervisionar, regulamentar, ou mesmo incentivar a prática dos desportos em todo o país.

Segundo Carvalho (2013, p. 41-42), as manifestações esportivas, anteriores à Constituição de 1988, também chamada de Constituição Cidadã, "se caracterizam por ideias de valores nacionalistas de disciplina e de valorização da manifestação do esporte de rendimento, por um arranjo institucional corporativista, normativo e fiscalizador e pela ação de um grupo seleto na formulação de políticas para o setor".

Entretanto, com a referida constituição, o esporte passa a ser colocado em uma ordem discursiva que o produz não mais somente como prática que precisa ser fiscalizada, orientada ou regulada, mas como um direito garantido pelo Estado a cada um dos cidadãos brasileiros.

Com a implementação da Constituição Cidadã, o papel estatal passa a ser desempenhado no sentido de garantir o esporte com uma diversificada e constante forma de atuação no cotidiano das pessoas, garantindo-o enquanto um direito a cada um dos cidadãos brasileiros. Tem-se, então, que "a força da Constituição Federal influenciou sobremaneira a década de 1990, que pode ser considerada um período de mudanças fundamentais para o esporte brasileiro" (AZEVEDO, 2008, p.20).

Indico assim a referida legislação enquanto um acontecimento ${ }^{9}$ de um discurso legislativo, que opera como uma das estratégias de produção de verdade em uma época determinada e que busca compor o esporte tal como ele funciona na atualidade, como um direito de cada brasileiro a ser garantido pelo Estado e que nesta produção textual passa a ser problematizado.

8 Evoca-se a noção de população a partir de Foucault (2008a, p. 292). Não se trata da invenção de um termo, mas da ênfase a uma nova dimensão analítica do ser humano, entendida como uma massa global composta de um conjunto de seres vivos, se não infinita, pelo menos, necessariamente, mensurável e, assim sendo, suscetível de ações, controle, assegurando uma melhor gestão da sua força produtiva.

9 Neste trabalho estou acionando o termo acontecimento a partir da noção indicada por Castro (2009, p. 25), como acontecimento discursivo, ou seja, aquele em que a arqueologia descreve enquanto enunciados, e que leva em consideração "as condições de existência que determinam a materialidade própria do enunciado" (CASTRO, 2009, p. 25). 
É nesse movimento que destaco inicialmente a Lei oㅜ 8.672, de 06/07/1993, implementada no governo de Itamar Franco, período esse de grande turbulência vivido pelo Brasil, visto que o país vinha de um processo de impeachment do então presidente Fernando Collor de Mello, ocasionado por uma recessão prolongada, inflação aguda e crônica, desemprego etc. Destaca-se, também, como importante neste contexto, a implantação do Plano Real, sob a incumbência de efetivar um controle inflacionário. Têm-se, ainda, em abril de 1993, a realização de um plebiscito em que o povo fez a escolha da forma e do sistema de governo no Brasil.

Foi nesse cenário político, social e econômico que foi implementada a Lei no 8.672/93, popularmente chamada Lei Zico, evocando aquilo que é demarcado na Constituição de 1988, ou seja, o esporte como um direito individual, e instituindo uma série de princípios fundamentais para garanti-lo. Conforme pode ser observado no capítulo abaixo:

\section{CAPÍTULO II}

\section{DOS PRINCÍPIOS FUNDAMENTAIS}

Art. $2^{\circ} \mathrm{O}$ desporto, como direito individual, tem como base os seguintes princípios: I - soberania, caracterizado pela supremacia nacional na organização da prática desportiva;

II - autonomia, definido pela faculdade de pessoas físicas e jurídicas organizarem-se para a prática desportiva como sujeitos nas decisões que as afetam;

III - democratização, garantido em condições de acesso às atividades desportivas sem distinções e quaisquer formas de discriminação;

IV - liberdade, expresso pela livre prática do desporto, de acordo com a capacidade e interesse de cada um, associando-se ou não a entidades do setor;

$V$ - direito social, caracterizado pelo dever do Estado de fomentar as práticas desportivas formais e não-formais;

VI - diferenciação, consubstanciado no tratamento específico dado ao desporto profissional e não-profissional;

VII - identidade nacional, refletido na proteção e incentivo às manifestações desportivas de criação nacional;

VIII - educação, voltado para o desenvolvimento integral do homem como ser autônomo e participante e fomentado através da prioridade dos recursos públicos ao desporto educacional;

IX - qualidade, assegurado pela valorização dos resultados desportivos, educativos e dos relacionados à cidadania e ao desenvolvimento físico e moral;

$X$ - descentralização, consubstanciado na organização e funcionamento harmônicos de sistemas desportivos diferenciados e autônomos para os níveis federal, estadual e municipal;

XI - segurança, propiciado ao praticante de qualquer modalidade desportiva, quanto a sua integridade física, mental ou sensorial;

XII - eficiência, obtido através do estímulo à competência desportiva e administrativa. (BRASIL, 1993)

Demarco, igualmente como relevante, o capítulo desta mesma lei que institui as normas gerais sobre o desporto, como pode ser observado no trecho abaixo:

\section{CAPÍTULO I}

DISPOSIÇÕES INICIAIS

Art. 100 desporto brasileiro abrange práticas formais e não-formais e obedece às normas gerais desta Lei, inspirado nos fundamentos constitucionais do Estado 
$\S 1$ - A prática desportiva formal é regulada por normas e regras nacionais e pelas regras internacionais aceitas em cada modalidade.

§ 2ํ A prática desportiva não-formal é caracterizada pela liberdade lúdica de seus praticantes. (BRASIL, 1993)

Ao se referir a práticas formais e não formais para designar a abrangência do esporte, ocorre um aumento de ingerência na concepção do mesmo, visto que as legislações anteriores aludiam somente às práticas esportivas como aquelas de características físicas e de caráter competitivo, como pode ser visualizado na Lei 6.251 , de 8 de outubro de 1975, em seu artigo 2․․

Para os efeitos desta Lei, considera-se desporto a atividade predominantemente física, com finalidade competitiva exercitada segundo regras pré-estabelecidas (BRASIL, 1975).

Entretanto, com a implementação da Lei Zico demarca-se um aumento da abrangência da noção de esporte que também pode ser observada em seu capítulo III:

CAPÍTULO III

\section{DA CONCEITUAÇÃO E DAS FINALIDADES DO DESPORTO}

Art. 300 desporto como atividade predominantemente física e intelectual pode ser reconhecido em qualquer das seguintes manifestações: (BRASIL, 1993)

Ao caracterizar o desporto como atividade física e intelectual, que compreende práticas formais e não formais, alarga-se seu envolvimento, ou seja, a concepção de esporte se liberta das amarras de se referir somente a atividades físicas praticadas com caráter competitivo, que atingem um grupo delimitado de pessoas, para ser concebida como toda e qualquer atividade física e intelectual, que possa ser caracterizada como formal e não formal. Assim sendo, há um alargamento da abrangência de seu conceito, tornando-o presente e acessível a um número maior de pessoas, ou mesmo atingindo uma parcela maior da população brasileira com as práticas assumidas, a partir dessa lei, como esportivas.

Na sequência desse mesmo documento, ressalto também, como relevante, as três alíneas em que são conceituados os desportos e definidas suas finalidades,

\section{CAPÍTULO III}

\section{DA CONCEITUAÇÃO E DAS FINALIDADES DO DESPORTO}

Art. $3^{\circ} \mathrm{O}$ desporto como atividade predominantemente física e intelectual pode ser reconhecido em qualquer das seguintes manifestações:

I - desporto educacional, praticado nos sistemas de ensino e em formas assistemáticas de educação, evitando-se a seletividade, a hipercompetitividade de seus praticantes, com a finalidade de alcançar o desenvolvimento integral do indivíduo e a sua formação para o exercício da cidadania e a prática do lazer;

II - desporto de participação, de modo voluntário, compreendendo as modalidades desportivas praticadas com a finalidade de contribuir para a integração dos praticantes na plenitude da vida social, na promoção da saúde e educação e na preservação do meio ambiente;

III - desporto de rendimento, praticado segundo normas gerais desta Lei e regras de prática desportiva, nacionais e internacionais, com a finalidade de obter resultados e integrar pessoas e comunidades do País e estas com as de outras nações. (BRASIL, 1993)

Ao classificar o desporto como educacional, de participação e de rendimento, delimitando também suas finalidades, vai se evidenciando um regime de verdades que toma a prática 
do esporte como uma das fundamentais ferramentas para o desenvolvimento integral dos indivíduos e para a produção de sujeitos integrados socialmente, saudáveis, educados, atuantes na preservação do meio ambiente e no exercício de sua cidadania.

Cito ainda a Lei no 9.615 de 24/03/1998, que substituiu a Lei Zico e foi popularizada como Lei Pelé (TUBINO, 2002, p. 37), que expressa, em seu Capítulo III:

\section{DA NATUREZA E DAS FINALIDADES DO DESPORTO \\ Art. $3^{\circ} \mathrm{O}$ desporto pode ser reconhecido em qualquer das seguintes manifesta- ções: \\ I - desporto educacional, praticado nos sistemas de ensino e em formas assiste- máticas de educação, evitando-se a seletividade, a hipercompetitividade de seus praticantes, com a finalidade de alcançar o desenvolvimento integral do indivíduo e a sua formação para o exercício da cidadania e a prática do lazer; \\ II - desporto de participação, de modo voluntário, compreendendo as modalida- des desportivas praticadas com a finalidade de contribuir para a integração dos praticantes na plenitude da vida social, na promoção da saúde e educação e na preservação do meio ambiente; \\ III - desporto de rendimento, praticado segundo normas gerais desta Lei e regras de prática desportiva, nacionais e internacionais, com a finalidade de obter resulta- dos e integrar pessoas e comunidades do País e estas com as de outras nações. (BRASIL, 1998)}

Percebe-se, uma alteração no título do referido capítulo, que antes era chamado "Da conceituação e das finalidades do desporto" e passa agora a ser nomeado "Da natureza e das finalidades do desporto". Assim sendo, mais do que uma simples mudança de termos utilizados, essa maneira de se referir ao desporto busca consolidar sua existência na sociedade brasileira, visto que, na Lei Zico, o esporte precisava ser conceituado, definido, mas já na Lei Pelé ele passa a ser tratado como uma instância que possui uma natureza constituidora, que não mais necessita ser explicada e que é espontaneamente aceita por todos.

Demarco ainda a concepção de esporte, que na legislação no 8.672 era limitado a qualquer atividade física e intelectual e que, a partir da lei 9.615, passa a ser referido como toda manifestação que seja concebida como educacional, de participação ou ainda de rendimento, o que expande ainda mais a noção de esporte, abrangendo um número maior de atividades e de sujeitos passíveis de serem definidos.

\section{ENFIM...}

O presente texto foi elaborado movido pela curiosidade de problematizar as verdades que constituem nosso cotidiano, mas não no sentido de desconstruir algo ou mesmo de questionar se uma instância é verdadeira ou falsa, certa ou errada, válida ou inválida, mas, isso sim, em um movimento de buscar perceber "o conjunto das práticas discursivas ou não discursivas que faz alguma coisa entrar no jogo do verdadeiro e do falso e o constitui como objeto para 0 pensamento" (FOUCAULT, 2006b, p. 242).

Especificamente, nesta produção textual, ao colocar em operação algumas ferramentas da genealogia foucaultiana, imbricada com a arqueologia, foi possível diagnosticar as condições e as possibilidades que passaram a atuar no Brasil, constituindo uma verdade que busca produzir o esporte como um direito, garantido pelo Estado, a todos os cidadãos. 
Através do olhar lançado sobre as leis e decretos, implementados no Brasil a partir da Constituição de 1988, foi se evidenciando um regime de verdades que vincula a prática do esporte como um direito enquanto uma das fundamentais ferramentas para o desenvolvimento integral dos indivíduos e para a produção de sujeitos integrados socialmente, saudáveis, educados, atuantes na preservação do meio ambiente e no exercício de sua cidadania.

Observou-se, ainda, a recorrência de enunciados diversos que vão ampliando a concepção de esporte, produzindo-o como uma verdade que invade a vida das pessoas, tornando-se assim naturalmente aceita por todos.

Ao finalizar este texto gostaria de fazê-lo não de uma forma peremptória, assumindo um sentido de terminalidade, ou mesmo de esgotamento de possibilidades, mas salientando a necessidade de se buscar outras imagens, de viajar por outros horizontes, procurando vislumbrar outros caminhos que tornem possível compreender a composição do esporte em suas diversas manifestações no nosso cotidiano.

\section{REFERÊNCIAS}

ARTIĖRES, Philippe. Entrelinhas: ler os arquivos de Michel Foucault. In: SCAVONE, Lucila; ALVAREZ, Marcos Cesar; MISKOLCI, Richard (Org.). O legado de Foucault. São Paulo: UNESP, 2006.

AZEVEDO, Aldo Antonio (Org.). Torcedores, mídia e políticas públicas de esporte e lazer no distrito federal. Brasília: Thesaurus, 2008.

ASSMANN, Selvino José; NUNES, Nei Antonio. Michel Foucault e a genealogia como crítica do presente. Revista Internacional Interdisciplinar. Interthesis, Florianópolis, v 4. n.1. jan.jun. 2007. Disponível em $<$ <ww.periodicos.ufsc.br/index.php/interthesis/article/view/88- 77k>. Acesso em: 28 jan. 2012.

BRASIL. (Constituição, 1988). Constituição da República Federativa do Brasil: promulgada em 5 de outubro de 1988. Porto Alegre: Assembleia do Estado do Rio Grande do Sul, 1988.

BRASIL. Decreto-Lei no 526, de 1 de julho de 1938. Institui o Conselho Nacional de Cultura.. Disponível em: <http://www2.camara.leg.br/legin/fed/declei/1930-1939/decreto-lei-526-1-julho-1938358396-publicacaooriginal-1-pe.html>. Acesso em: 12 mar. 2014.

BRASIL. Decreto-Lei no 1.056, de 19 de janeiro de 1939. Institui a Comissão Nacional de Desportos. Disponível em: <http://www2.camara.leg.br/legin/fed/declei/1930-1939/decreto-lei-1056-19-janeiro1939-349204-publicacaooriginal-1-pe.htmk. Acesso em: 24 nov. 2013.

BRASIL. Decreto-Lei no 3.199, de 14 de abril de 1941. Estabelece as bases de organização dos desportos em todo o país. Disponível em: <http://legis.senado.gov.br/legislacao/ListaPublicacoes. action?id=152593<. Acesso em: 2 dez. 2013.

BRASIL. Lei no 6.251, de 8 de outubro de 1975. Institui normas gerais sobre desportos, e dá outras providências. Disponível em <http://www010.dataprev.gov.br/sislex/páginas/42/1975/6251.htm>. Acesso em: 24 fev. 2013.

BRASIL. Lei no 8.672, de 6 de julho de 1993. Institui normas gerais sobre desportos e dá outras providências. Disponível em: <http://www2.camara.leg.br/legin/fed/lei/1993/lei-8672-6-julho-1993349784-norma-pl.html>. Acesso em: 24 fev. 2013.

BRASIL. Lei no 9.615, de 24 de março de 1998. Institui normas gerais sobre desporto e dá outras providências. Disponível em: http://www.planalto.gov.br/ccivil 03/leis//9615consol.htm. Acesso em: 06 ago. 2013

BUENO, Luciano. Políticas públicas do esporte no Brasil: razões para o predomínio do alto rendimento. 2008. 292 f. Tese (Doutorado em Administração Pública e Governo) - Escola de 
Administração de Empresas de São Paulo, Fundação Getúlio Vargas, São Paulo, 2008.

CARVALHO, Cesar Machado de. Esporte como política pública: um estudo sobre o processo de formulação da política de esporte no Brasil. 2013. 110 f. Dissertação (Mestrado em Ciência Política) Centro de Educação em Ciências Humanas, Universidade Federal de Campinas, São Carlos, 2013.

CASTRO, Edgardo. Vocabulário de Foucault: um percurso pelos seus temas, conceitos e autores. Belo Horizonte. Autêntica Editora: 2009.

FISCHER, Rosa Maria Bueno. A paixão de trabalhar com Foucault. In: COSTA, Marisa Vorraber (Org.). Caminhos investigativos: novos olhares na pesquisa em educação. 2. ed. Rio de Janeiro: DP\&A, 2007.

FOUCAULT, Michel. A arqueologia do saber. Tradução de Luiz Felipe Baeta Neves; 6. ed. Rio de Janeiro: Forense Universitária, 2002.

FOUCAULT, Michel. Aula de 17 de março de 1976. In: SEGURANÇA, território, população. Curso dado no College de France (1977-1978). Edição estabelecida por Michel Senellart sob a direção de François Ewald e Alessandro Fonseca; tradução Eduardo Brandão; revisão de Alessandro Fontana; tradução Claudia Berliner. São Paulo: Martins Fontes, 2008a.

FOUCAULT, Michel. Conversas com Michel Foucault. In: MOTTA, Manoel Barros da (Org.). Ditos e escritos IV: repensar a política. Tradução de Ana Lúcia Paranhos Pessoa. Rio de Janeiro: Forense Universitária, 2010a.

FOUCAULT, Michel. O filósofo mascarado. In: MOTTA, Manoel Barros da (Org.). Ditos e escritos II: Arqueologia das ciências e história dos sistemas de pensamento. Tradução de Elisa Monteiro. Rio de Janeiro: Forense Universitária, 2008b.

FOUCAULT, Michel. A governamentalidade. In: MOTTA, Manoel Barros da (Org.). Ditos e escritos IV: estratégia, poder-saber. Tradução de Vera Lucia Avellar Ribeiro. 2. ed. Rio de Janeiro: Forense Universitária, 2006a.

FOUCAULT, Michel. Mesa redonda em 20 de maio de 1978. In: MOTTA, Manoel Barros da (Org.).

Ditos e escritos IV: estratégia, poder-saber. Tradução de Vera Lucia Avellar Ribeiro. 2. ed. Rio de Janeiro: Forense Universitária, 2006b.

FOUCAULT, Michel. A ordem do discurso: aula inaugural no College de France, pronunciada em 2 de dezembro de 1970. Tradução de Laura Fraga de Almeida Sampaio. 13. ed. São Paulo, Loyola, 1996.

FOUCAULT, Michel. Para uma moral do desconforto. In: MOTTA, Manoel Barros da (Org.). Ditos e escritos IV: repensar a política. Tradução de Ana Lúcia Paranhos Pessoa. Rio de Janeiro: Forense Universitária, 2010b.

FOUCAULT, Michel. Polêmica, política e problematizações. In: MOTTA, Manoel Barros da (Org.).

Ditos e escritos V: ética, sexualidade, política. Tradução de Elisa Monteiro, Inês Autran Dourado Barbosa. Rio de Janeiro: Forense Universitária, 2006b.

LYRA FILHO, João. Direito desportivo, Rio de Janeiro: Pongetti, 1952.

NIETZSCHE, Friedrich. 0 viajante e sua sombra. Tradução de Antonio Carlos Braga e Ciro Mioranza. São Paulo: Escala, 2007.

PANDOLFI, Dulce (Org.). Repensando o Estado Novo. Rio de Janeiro: Ed. Fundação Getulio Vargas, 1999.

SOARES, Carmen Lúcia. As roupas nas práticas corporais e esportivas: a educação do corpo entre o conforto, a elegância e a eficiência (1920-1940). Campinas, SP: Autores Associados, 2011.

TUBINO, Manoel José Gomes. 500 anos de legislação esportiva brasileira: do Brasil colônia ao início do século XXI. Rio de Janeiro: Shape, 2002.

VILELA, Eugénia. Resistência e acontecimento: as palavras sem centro. In: KOHAN, Walter Omar; GONDRA, José (Org.). Foucault 80 anos. Belo Horizonte: Autêntica, 2006.

WILLIAMS, James. Pós-estruturalismo. 2. ed. Rio de Janeiro: Vozes, 2013. 